\title{
Hardware-in-the-loop based comparative analysis of speed controllers for a two-mass system using an induction motor drive with ideal stator current performance
}

\author{
Vo Thanh $\mathrm{Ha}^{1}$, Tung Lam Nguyen ${ }^{2}$, Vo Thu $\mathrm{Ha}^{3}$ \\ ${ }^{1}$ Faculty of Electrical and Electrical Engineering, University of Transport and Communications, Vietnam \\ ${ }^{2}$ School of Electrical Engineering, Hanoi University of Science and Technology, Vietnam \\ ${ }^{3}$ Faculty of Electrical Engineering, University of Economics-Technology for Industries, Vietnam
}

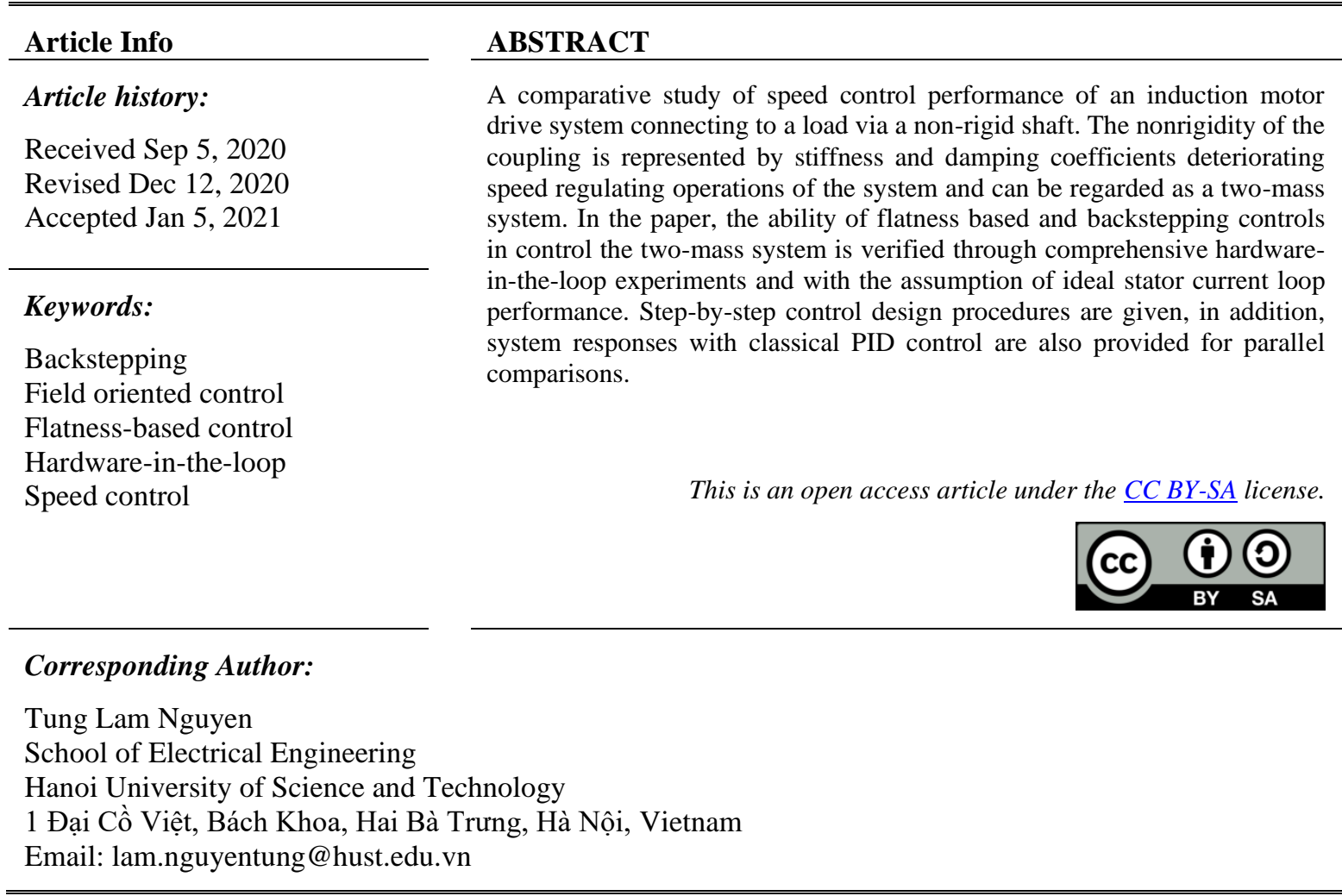

\section{INTRODUCTION}

Asynchronous electrical drive system is found in enormous applications and is considered as wellestablished thank to the advancement in current loop control [1]. However, facing mechanical loads, speed control loop design takes a decisive role, especially when the non-rigidity and backlash of the motor-to-load connection is taken into account [2-5]. Flexible coupling phenomenon is studied in [6], the authors develop an elegant control scheme integrated with a state observer for estimating motor and load torques. Brock et al. [7] propose a filter accompanied with a neural adaptive controller to eliminate high resonance frequencies. The controlled system is analysed through extensive experiments proving the effectiveness of the proposed solution. For a class of multi-mass electrical drive systems where measurement is not always available, a system parameter identification method is presented in [8]. The authors employ pseudo random binary signal and chirp wave to excite necessary information. The approach might be difficult to apply in a wide range of practical systems. A 2DOF PI control is systematically designed in [9] for a two-mass drive coupled via a toothed belt. The tracking results are compared with $1 \mathrm{DOF}$ and $1 \mathrm{DOF}$ with feedforward controls confirm that the method exhibits robustness and load torque rejection. Due to flat property of the system, Thomsen et al. [10] formulate a flatness based control for a finite stiffness coupling drive system fed by an inverter with speed feedback signal. Backstepping control is developed for a multi-motor system which is vastly found in 
rewinding systems in [11] suppressing flexible coupling phenomenon in linear speed and tension control system. In order to deal with nonlinear stiffness, the authors in [12] implement adaptive backstepping to reduce connecting shaft oscillations. However, system stiffness characteristic must be known to carry out the control, this requirement might be very challenging in practice. Recently, a active disturbance rejection control (ADRC) is considered as an alternative to classical PID control, an application of ADRC to two-mass system can be found in [13]. A fuzzy based control for a three-mass system is presented in [14, 15], where fuzzy term is selected to modify IPD control. Other control approaches can be found in [16-22].

In general, there is a lack of comprehensive study on how popular control methods react when applying to two-mass drive system operating in nominal range. In the paper, we carry out a hardware-in-theloop based comparative analysis of speed responses using backstepping and flatness-based controls in nominal and field-weakening modes. Initially, we present the two-mass drive system in a view of ideal current loop. Subsequently, PID, backstepping, and flatness control design steps are given in details. Finally, hardware-in-the-loop results of three controls are compared and some important conclusions are drawn.

\section{TWO-MASS MODEL SYSTEM WITH IDEAL CURRENT LOOP RESPONSE}

Typical configuration of a two-mass system is shown in Figure 1.

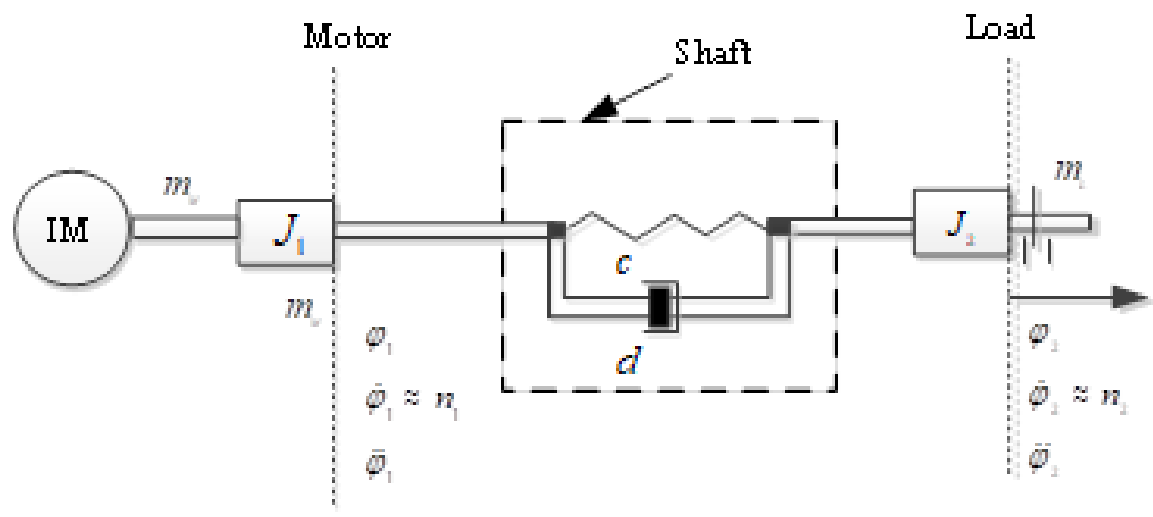

Figure 1. Typical configuration of a two-mass system

When operating in field weakening region, the model of the system can be given as [2].

$$
\begin{aligned}
& \frac{d i_{s d}}{d t}=-\left(\frac{1}{\sigma T_{s}}+\frac{1-\sigma}{\sigma T_{r}}\right) i_{s d}+\omega_{s} i_{s q}+\frac{1-\sigma}{\sigma T_{r}}+\frac{1}{\sigma L_{s}} u_{s d} \\
& \frac{d i_{s q}}{d t}=-\omega_{s} i_{s d}-\left(\frac{1}{\sigma T_{s}}+\frac{1-\sigma}{\sigma T_{r}}\right) i_{s q}-\frac{1-\sigma}{\sigma} \omega i_{m}+\frac{1}{\sigma L_{s}} u_{s q} \\
& \frac{d \psi_{r d}}{d t}=-\frac{1}{T_{r}} \psi_{r d}+\frac{L_{m}}{T_{r}} i_{s d} \\
& \frac{d \psi_{r q}}{d t}=\frac{L_{m}}{T_{r}} i_{s q}-\left(\omega_{s}-\omega\right) \psi_{r d} i_{s d}-\frac{1}{T_{r}} \psi_{r q} \frac{\psi_{r q}}{L_{m}} \\
& \ddot{\varphi}_{1}=-\frac{d}{J_{1}} \dot{\varphi}_{1}-\frac{c}{J_{1}} \Delta \varphi+\frac{d}{J_{1}} \dot{\varphi}_{2}+\frac{1}{J_{1}} m_{M} \\
& \Delta \dot{\varphi}=\dot{\varphi}_{1}-\dot{\varphi}_{2} \\
& \ddot{\varphi}_{2}=\frac{d}{J_{2}} d / J_{2} \dot{\varphi}_{1}+\frac{c}{J_{2}} \Delta \varphi-\frac{d}{J_{2}} \dot{\varphi}_{2}-\frac{1}{J_{2}} m_{L}
\end{aligned}
$$

In which, $i_{s d} ; i_{s q}$ are $d q$ components of the stator current; $\omega, \omega_{s}$ rotor and synchronous speeds, respectively; $\psi_{r d}^{\prime}, \psi_{r q}^{\prime}$ are rotor flux $d q$ components; $\sigma$ is total leakage factor; $T_{r}$ is rotor time constant: $u_{s d}$, $u_{s q}$ are stator voltage $d q$ components; $L_{s}$ is stator inductance, $\dot{\varphi}_{1}, \dot{\varphi}_{2}$ are motor and load speeds; $\ddot{\varphi}_{1}, \ddot{\varphi}_{2}$ are motor and load angle accelerations; $\varphi$ is rotor angle; $d$ is the coupling shaft damping coefficient; $c$ is shaft 
stiffness. It can be seen that the system of dynamical (1) is of $7^{\text {th }}$ order. With the assumption of t perfectly designed current controller, the system model can be reduced as:

$$
\begin{aligned}
& \frac{d i_{m}}{d t}=\frac{1}{T_{r}} i_{s d}-\frac{1}{T_{r}} i_{m} \\
& \ddot{\varphi}_{1}=-\frac{d}{J_{1}} \dot{\varphi}_{1}-\frac{c}{J_{1}} \Delta \varphi+\frac{d}{J_{1}} \dot{\varphi}_{2}+\frac{1}{J_{1}} m_{M} \\
& \Delta \dot{\varphi}=\dot{\varphi}_{1}-\dot{\varphi}_{2} \\
& \ddot{\varphi}_{2}=\frac{d}{J_{2}} \dot{\varphi}_{1}+\frac{c}{J_{2}} \Delta \varphi-\frac{d}{J_{2}} \dot{\varphi}_{2}-\frac{1}{J_{2}} m_{L}
\end{aligned}
$$

where: $i_{m}=\frac{\psi_{r d}}{L_{m}}$. The state (2) is of $4^{\text {nd }}$ order, stator current $i_{s d}$ is used to control the motor flux and $i_{s q}$ is dedicated to speed control. For control design purpose (2) is rewritten in the following state-space form:

$$
\left[\begin{array}{c}
i_{m} \\
\ddot{\varphi}_{1} \\
\Delta \dot{\varphi} \\
\ddot{\varphi}_{2}
\end{array}\right]=\left[\begin{array}{cccc}
\frac{-1}{T_{r}} & 0 & 0 & 0 \\
0 & \frac{-d}{J_{1}} & \frac{-c}{J_{1}} & \frac{d}{J_{1}} \\
0 & 1 & 0 & \frac{-1}{0} \\
0 & \frac{d}{J_{2}} & \frac{c}{J_{2}} & \frac{-d}{J_{2}}
\end{array}\right]\left[\begin{array}{c}
i_{m} \\
\dot{\varphi}_{1} \\
\Delta \varphi \\
\dot{\varphi}_{2}
\end{array}\right]+\left[\begin{array}{cc}
\frac{1}{T_{r}} & 0 \\
0 & \frac{k_{\omega} i_{m}}{J_{1}} \\
0 & 0 \\
0 & 0
\end{array}\right]\left[\begin{array}{c}
i_{s d} \\
i_{s q}
\end{array}\right]+\left[\begin{array}{c}
0 \\
0 \\
0 \\
\frac{-1}{J_{2}}
\end{array}\right] m_{L}
$$

where we have defined,

$$
y^{T}=\left[i_{m}, \dot{\varphi}_{2}\right] ;\left[\begin{array}{c}
i_{m} \\
\dot{\varphi}_{2}
\end{array}\right]=\left[\begin{array}{llll}
1 & 0 & 0 & 0 \\
0 & 0 & 0 & 1
\end{array}\right]\left[\begin{array}{c}
i_{m} \\
\dot{\varphi}_{1} \\
\Delta \varphi \\
\dot{\varphi}_{2}
\end{array}\right]
$$

\section{SPEED CONTROL DESIGN}

\subsection{PI control}

PI controller is designed according to the symmetric optimal standard, so we have the PI control structure shown as Figure 2. The design of PI for the system is well-established, readers can refer to [23, 24] for more details.

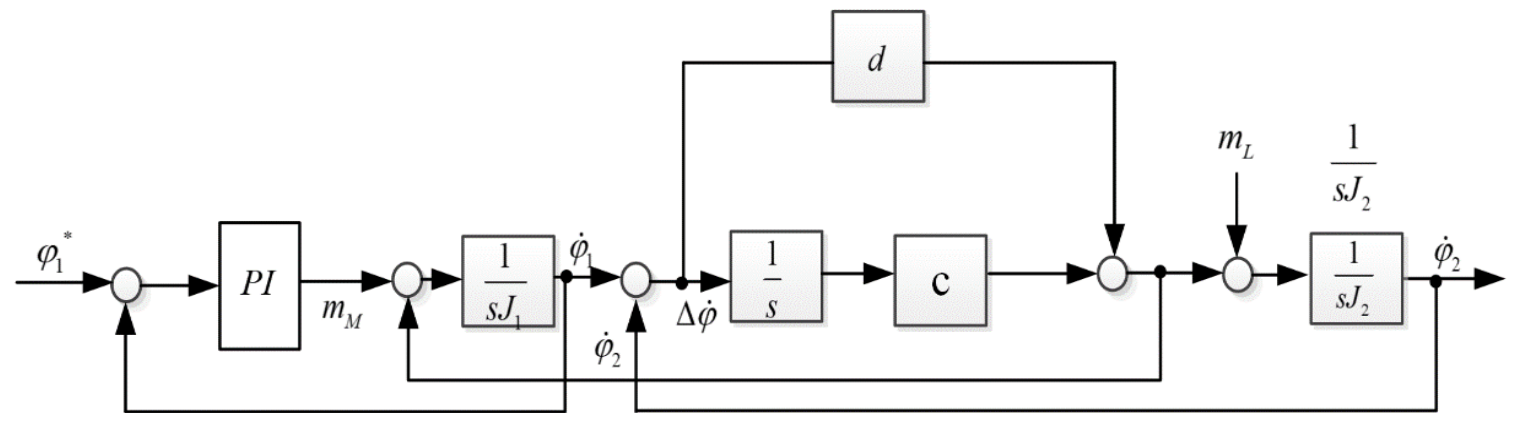

Figure 2. Block diagram of PI control algorithm of a two-mass system

\subsection{Backstepping control}

For designing step, it is assumed that all feedback signals from the motor, the shaft and the load sides are available. As in Figure 2, the backstepping control is divided into two steps. In each step, a subsystem will be studied and controlled. Selecting a proper Lyapunov candidate function for each design step can guarantees the asymptotic stability of the corresponding subsystem. After completing all two steps, the asymptotic stability of the whole system can be achieved [25]. The speed control equation is given: 


$$
\begin{gathered}
\frac{d \dot{\varphi}_{2}}{d t}=-\frac{d}{J_{2}} \dot{\varphi}_{2}+\frac{c}{J_{2}} \Delta \varphi+\frac{d}{J_{2}} \dot{\varphi}_{1}-\frac{1}{J_{2}} m_{L} \\
\frac{d \dot{\varphi}_{1}}{d t}=-\frac{d}{J_{1}} \dot{\varphi}_{1}-\frac{c}{J_{1}} \Delta \varphi+\frac{d}{J_{1}} \dot{\varphi}_{2}-\frac{k_{\omega} \cdot \psi_{r d}^{\prime}}{J_{1}} i_{s q}
\end{gathered}
$$

where $m_{M}=k_{\omega}\left(\psi_{r d} / L_{m}\right) i_{s q} ; k_{\omega}=(3 / 2) z_{p}\left(L_{m} / L_{r}\right)$ is motor torque. For ease of deploying control design, we define:

$$
\begin{gathered}
x_{1}=\dot{\varphi}_{2} \\
x_{2}=\dot{\varphi}_{1} \\
u=i_{s q} \\
y=x_{1}=\dot{\varphi}_{2}
\end{gathered}
$$

where $x_{1}$ and $x_{2}$ are state variables; $u$ is the control input and $y$ is the output (the load rotating speed). Since then the system is expressed in the strict feedback form as (7):

$$
\begin{gathered}
\dot{x}_{1}=\left(\frac{d \dot{\varphi}_{2}}{d t}\right)=f_{1}\left(x_{1}, x_{2}\right) \\
\dot{x}_{2}=\left(\frac{d \dot{\varphi}_{1}}{d t}\right)=f_{2}\left(x_{1}, x_{2}, u\right) \\
y=x_{1}=\dot{\varphi}_{2}
\end{gathered}
$$

In order to implement backstepping control we define:

$$
\begin{aligned}
& z_{1}=x_{1}-x_{1 d}=\dot{\varphi}_{2}-\dot{\varphi}_{2 d} \\
& z_{2}=x_{2}-x_{2 d k a}=\dot{\varphi}_{1}-\dot{\varphi}_{1 d k a}
\end{aligned}
$$

where $x_{1 d}=\dot{\varphi}_{2 d}$ is the set value of the output variable and $x_{2 d k a}=\dot{\varphi}_{1 d k a}$ is the virtual control. Selecting the Lyapunov candidate function as (9):

$$
V_{1}=\frac{1}{2} z_{1}^{2}
$$

Taking derivative of (9) results in:

$$
\dot{V}_{1}=z_{1} \dot{z}_{1}
$$

Because of $\ddot{\varphi}_{1 d}=0$ so that (8) rendered as $\dot{z}_{1}=\ddot{\varphi}_{2}$, substitution $\dot{z}_{1}$ from (5) into (10) yields:

$$
\dot{V}_{1}=z_{1}\left[-k_{1} z_{1}+\frac{d}{J_{2}} \dot{\varphi}_{1}+\left(k_{1} z_{1}+\frac{c}{J_{2}} \Delta \varphi-\frac{1}{J_{2}} m_{L}-\frac{d}{J_{2}} \dot{\varphi}_{2}\right)\right]
$$

Considering $\dot{\varphi}_{1}$ as the virtual control variable in such a way that $\dot{\varphi}_{1}=\dot{\varphi}_{1 d k a}$ so that:

$$
\frac{d}{J_{2}} \dot{\varphi}_{1 d k a}=-\left(k_{1} z_{1}+\frac{c}{J_{2}} \Delta \varphi-\frac{1}{J_{2}} m_{L}-\frac{d}{J_{2}} \dot{\varphi}_{2}\right)
$$

If $\dot{V}_{1}=-k_{1} z_{1}^{2}<0$, with $\forall k_{1}>0$ then the stable condition is satisfied. Defining:

$$
B_{f}=\frac{c}{J_{2}} \Delta \varphi-\frac{1}{J_{2}} m_{L}-\frac{d}{J_{2}} \dot{\varphi}_{2}
$$

Substitution of (13) into (12) results in:

$$
\dot{\varphi}_{1 d k a}=-\frac{J_{2}}{d}\left[k_{1} z_{1}+B_{f}\right]
$$

The control specified in (14) ensures that the load speed tracks the desired value. Next, the control for the motor side is designed. It is noted that $x_{1 d}=\dot{\varphi}_{2 d}$ is constant, so that from (5), (8), and (13) can be shortened as:

$$
\dot{z}_{1}=\frac{d \dot{\varphi}_{2}}{d t}=\ddot{\varphi}_{2}=\frac{d}{J_{2}} \dot{\varphi}_{1}+B_{f}
$$


Select the Lyapunov candidate function as (16):

$$
V_{2}=V_{1}+\frac{1}{2} z_{2}^{2}
$$

Taking derivative of (16) gives:

$$
\dot{V}_{2}=\dot{V}_{1}+z_{2} \dot{z}_{2}
$$

From (11) and (12), we can write as:

$$
\dot{V}_{2}=-k_{1} \dot{z}_{1}^{2}+\frac{d}{J_{2}} z_{1}\left(\dot{\varphi}_{1}-\dot{\varphi}_{1 d k a}\right)+z_{2} \dot{z}_{2}
$$

After some basic operations, it can be shown that:

$$
\dot{V}_{2}=-k_{1} \dot{z}_{1}^{2}-k_{2} z_{2}^{2}+k_{2} z_{2}^{2}+\frac{d}{J_{2}} z_{1}\left(\dot{\varphi}_{1}-\dot{\varphi}_{1 d k a}\right)+z_{2} \dot{z}_{2}
$$

where we have defined $\dot{\varphi}_{1}-\dot{\varphi}_{1 d k a}=z_{2}$, so that:

$$
\dot{V}_{2}=-k_{1} z_{1}^{2}-k_{2} z_{2}^{2}+z_{2}\left(k_{2} z_{2}+\frac{d}{J_{2}} z_{1}+\dot{z}_{2}\right)
$$

At this point in order to render $\dot{V}_{2}<0$, the following conditions must be fullfied:

$$
k_{2}>0 \text { and } k_{2} z_{2}+\frac{d}{J_{2}} z_{1}+\dot{z}_{2}=0
$$

Conditions specified in (21) imply that:

$$
\ddot{\varphi}_{1}-\ddot{\varphi}_{1 d k a}=-k_{2}\left(\dot{\varphi}_{1}-\dot{\varphi}_{1 d k a}\right)-\frac{d}{J_{2}} z_{1}
$$

From (14), it indicates that:

$$
\ddot{\varphi}_{1 d k a}=-\frac{J_{2}}{d}\left(k_{1} \dot{z}_{1}+\dot{B}_{f}\right) \text { and } \dot{\varphi}-\dot{\varphi}_{1 d k a}=\dot{\varphi}_{1}+\frac{J_{2}}{d}\left(k_{1} z_{1}+B_{f}\right)
$$

Substituting (15) and (22) into (23) gives:

$$
\ddot{\varphi}_{1}=-\left(k_{1}+k_{2}\right) \dot{\varphi}_{1}-\left(\frac{J_{2}}{d} k_{1} k_{2}+\frac{J_{2}}{d}\right) z_{1}-\frac{J_{2}}{d}\left(k_{1}+k_{2}\right) B_{f}-\frac{J_{2}}{d} \dot{B}_{f}
$$

To proceed to calculate the final expression of the control current, first of all, we substitution from the second equation of the system (5) into (24) we have:

$$
\frac{k_{\omega} \psi_{r d}^{\prime}}{J_{1}} \cdot i_{s q}=\left[\frac{d}{J_{1}}-\left(k_{1}+k_{2}\right)\right] \dot{\varphi}_{1}-\frac{d}{J_{1}} \dot{\varphi}_{2}+\frac{c}{J_{1}} \Delta \varphi-\left(\frac{J_{2}}{d} k_{1} k_{2}+\frac{d}{J_{2}}\right) z_{1}-\frac{J_{2}}{d}\left(k_{1}+k_{2}\right) B_{f}-\frac{J_{2}}{d} \dot{B}_{f}
$$

From the expression (25) and using fundamental calculation, we will get the final expression of $i_{s q}$ is:

$$
i_{s q}=\frac{J_{1}}{k_{\omega} \psi_{r d}^{\prime}}\left\{\begin{array}{c}
{\left[\frac{d}{J_{1}}+\frac{d}{J_{2}}-\left(\frac{c}{d}+k_{1}+k_{2}\right)\right]\left(\dot{\varphi}_{1}-\dot{\varphi}_{2}\right)+\left[\frac{c}{J_{1}}+\frac{c}{J_{2}}-\frac{c}{d}\left(k_{1}+k_{2}\right)\right] \Delta \varphi} \\
-\left(\frac{J_{2}}{d} k_{1} k_{2}+\frac{d}{J_{2}}\right)\left(\dot{\varphi}_{2}-\dot{\varphi}_{2 d}\right)+\frac{m_{w}}{d}\left(k_{1}+k_{2}-\frac{d}{J_{2}}\right)
\end{array}\right\}
$$

Based on (26), the proposed control structure for the two-mass system driven by the induction motor is shown in Figure 3. 


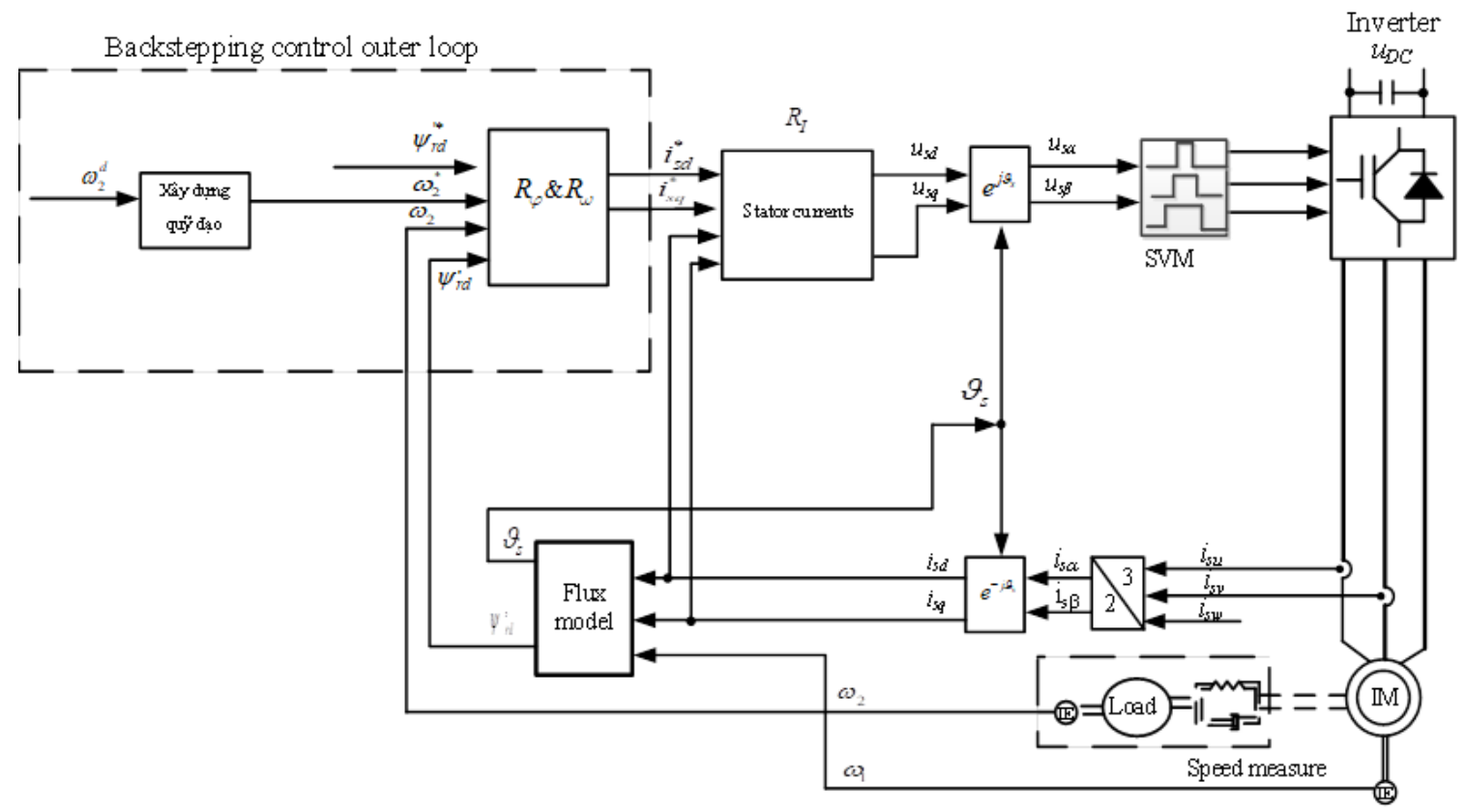

Figure 3. Block diagram of backstepping control algorithm of a two-mass system

\subsection{Flatness-based control (FBC)}

\subsubsection{Feedforward control design}

Feedforward control can be considered as the inverse mathematical model of the control object and plays a decisive role in the FBC structure. From (5), the feedforward control can be derived as:

$i_{s q}^{f f}=\frac{J_{1} \ddot{\varphi}_{1}+J_{2} \ddot{\varphi}_{2}+m_{L}}{k_{\omega} i^{*}{ }_{m}}$

$$
i_{s d}^{f f}=i_{m}^{*}+T_{r} \frac{d i_{m}^{*}}{d t}
$$

Based on equation $\ddot{\varphi}_{1}=-\frac{J_{2}}{J_{1}} \ddot{\varphi}_{2}+\frac{1}{J_{1}}\left(m_{M}-m_{L}\right)[26]$, it can be deduced that:

$$
J_{1} \dot{\omega}_{1}+J_{2} \dot{\omega}_{2}=m_{M}-m_{L}
$$

Assume that the load torque is not varying, then the load observer can be developed as:

$$
\frac{d \widehat{\omega}_{2}}{d t}=\frac{1}{J_{2}}\left(m_{M}-\widehat{m}_{L}-J_{1} \widehat{\omega}_{1}\right)+l_{2}\left(\widehat{\omega}_{2}-\omega_{2}\right) l_{1}\left(\widehat{\omega}_{2}-\omega_{2}\right)
$$

where $m_{M}=k_{\omega} i_{m} i_{s q}$. then from (28) and (29), it is straightforward to show that:

$$
\begin{gathered}
\frac{d\left(\widehat{m}_{L}-m_{L}\right)}{d t}=-l_{1}\left(\widehat{\omega}_{L}-\omega_{L}\right) \\
\frac{d\left(\widehat{\omega}_{L}-\omega_{L}\right)}{d t}=-\frac{1}{J_{2}}\left(\widehat{m}_{L}-m_{L}+J_{1} \widehat{\hat{\omega}}_{M}-J_{1} \dot{\omega}_{M}\right)+l_{2}\left(\widehat{\omega}_{L}-\omega_{L}\right)
\end{gathered}
$$

Defineing $\varepsilon_{m}=\widehat{m}_{L}-m_{L} ; \varepsilon_{\omega}=\widehat{\omega}_{L}-\omega_{L}$ and substituting into.(30) give:

$\frac{d \varepsilon_{\omega}}{d t}=-\frac{1}{J_{2}} \varepsilon_{m}+l_{2} \varepsilon_{\omega}+f\left(\widehat{\dot{\omega}}_{M}, \dot{\omega}_{M}\right)$

$$
\frac{d \varepsilon_{m}}{d t}=-l_{1} \varepsilon_{\omega}
$$

The error model is: 


$$
\left[\begin{array}{c}
\frac{d \varepsilon_{m}}{d t} \\
\frac{d \varepsilon_{\omega}}{d t}
\end{array}\right]=\left[\begin{array}{cc}
0 & -l_{1} \\
-\frac{1}{J_{2}} & l_{2}
\end{array}\right]\left[\begin{array}{l}
\varepsilon_{m} \\
\varepsilon_{\omega}
\end{array}\right]+\left[\begin{array}{l}
0 \\
f\left(\widehat{\hat{\omega}}_{M}, \dot{\omega}_{M}\right)
\end{array}\right]
$$

The characteristic equation of (32) is:

$$
\operatorname{det}[s \boldsymbol{I}-\boldsymbol{A}]=s^{2}-l_{2} s-\frac{l_{1}}{J_{2}}=0
$$

By selecting $l_{1}$ and $l_{2}$ such that:

$$
l_{1}=-J_{2} s_{1} s_{2} ; l_{2}=s_{1}+s_{2}
$$

\subsubsection{Design of the reference trajectories}

The equation $\boldsymbol{x}=P\left(\boldsymbol{y}, \frac{d \boldsymbol{y}}{d t}, \ldots, \frac{d^{r} \boldsymbol{y}}{d t^{r}}\right) ; r \in N ; \boldsymbol{u}=Q\left(\boldsymbol{y}, \frac{d \boldsymbol{y}}{d t}, \ldots, \frac{d^{(r+1)} \boldsymbol{y}}{d t^{(r+1)}}\right)$ is also called the "inverse" process model of the system corresponding to the output given in equation $\boldsymbol{y}=\left[\begin{array}{l}y_{1} \\ \vdots \\ y_{m}\end{array}\right]=F\left(\boldsymbol{x}, \boldsymbol{u}, \frac{d \boldsymbol{u}}{d t}, \ldots, \frac{d^{l} \boldsymbol{u}}{d t^{l}}\right) ; l \in$ $N$ Trajectories of flux reference:

$$
i_{m}^{*}+2 T_{1} \frac{d i_{m}^{*}}{d t}+T_{1}^{2} \frac{d^{2} i_{m}^{*}}{d t^{2}}=i_{m}^{d} \Leftrightarrow \frac{d^{2} i_{m}^{*}}{d t^{2}}=\frac{1}{T_{1}^{2}}\left(i_{m}^{d}-i_{m}^{*}-2 T_{1} \frac{d i_{m}^{*}}{d t}\right)
$$

- Speed reference trajectories

Trajectories of speed reference are given as:

where:

$$
\omega^{*}(t)=\left\{\begin{array}{cc}
\omega_{0}+a_{11} t+a_{21} t^{2}+a_{31} t^{3}+a_{41} t^{4} & 0 \leq t \leq 2 t_{0} \\
\omega_{0}+A t_{0}+A\left(t-2 t_{0}\right) & 2 t_{0}<t \leq t_{E}-2 t_{0} \\
a_{02}+a_{12} \tau+a_{22} \tau^{2}+a_{32} \tau^{3}+a_{42} \tau^{4} & t_{E}-2 t_{0}<t \leq t_{E}
\end{array}\right.
$$

$$
A=\frac{\omega_{E}-\omega_{0}}{t_{E}-2 t_{0}} ; \tau=t-\left(t_{c}-2 t_{0}\right) ; a_{11}=a_{21}=0 ; a_{31}=\frac{1}{4 t_{0}^{2}} A ; a_{41}=-\frac{1}{16 t_{0}^{3}} A
$$

\subsubsection{Feedback control design}

To handle the flux and the speed of the motor, the well-known PI controller is chosen. The detail equations of the flux and speed controller are described by (37) and (38), respectively:

$$
\begin{aligned}
& R_{\psi}=V_{\psi} \frac{1+d_{\psi^{z^{-1}}}}{1-z^{-1}} w i t h V_{\psi} \approx \frac{1}{3\left(1-e^{\frac{-T}{T_{r}}}\right)} ; d_{\psi} \approx e^{\frac{-T}{T_{r}}} \\
& \Delta i_{s q}=\frac{J_{1} J_{2} \Delta \ddot{\omega}_{2}+\left(d J_{1}+d J_{2}\right) \Delta \ddot{\omega}_{2}}{k_{\omega} i_{m} a c}+\frac{\left(J_{1} c+J_{2} a c\right) \Delta \dot{\omega}_{2}}{k_{\omega} i_{m} a c}
\end{aligned}
$$

where: $\Delta i_{s q}=i_{s q}^{*}-i_{s q}^{* f f} ; \Delta \omega_{2}=\omega_{2}-\omega_{2}^{*}$. Laplace transform of (38) provides the transfer function of error speed and flux:

$$
\frac{\Delta \omega_{2}(s)}{\Delta i_{s q}(s)}=\frac{k_{\omega} i_{m} a c}{s\left[J_{1} J_{2} s^{2}+\left(d J_{1}+d J_{2}\right) s+c J_{1}+a c J_{2}\right]}
$$

Based on feedforward and feedback control design and trajectories of speed and flux reference the proposed control scheme for the two-mass system driven by the induction motor with perfect stator current controller is shown in Figure 4. 


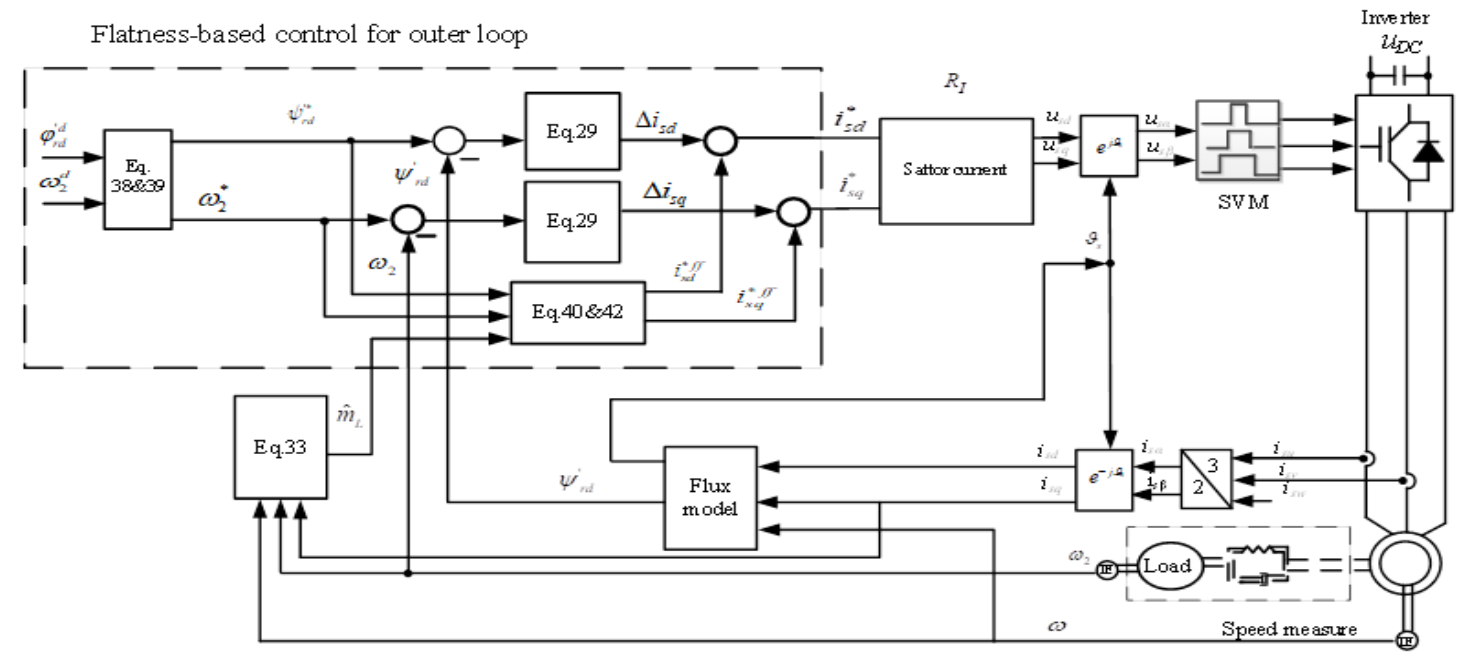

Figure 4. Block diagram flatness-based control of two-mass system

\section{RESULT AND DISCUSSION}

In this section, the proposed control strategy is verified by hardware-in-the-loop (HIL) simulation. The system hardware is simulated in real time on the HIL platform with a time step of $1 \mu$ s that means very close to physical models, while the pulse width modulation carrier frequency is $5 \mathrm{kHz}$. Voltage and current controllers are implemented in DSP TMS320F2808. The simulation parameters are: rated power $=2.2 \mathrm{~kW}$; rated phase voltage $=380 / 220$ VRMS; rated frequency $=50 \mathrm{~Hz} ; \mathrm{d}=0.015 \mathrm{Nm} / \mathrm{rad} ; \mathrm{c}=0.28 \mathrm{Nm} / \mathrm{rad}, \mathrm{J}_{1}=7.455$ $\mathrm{x} 10^{-5} \mathrm{Kgm}^{2} ; \mathrm{J} 2=5.5913 \times 10^{-5} \mathrm{Kgm}^{2}$; with load torque is $1.5 \mathrm{Nm}$.

Simulation scenario is: at $\mathrm{t}=0 \mathrm{~s}$, the magnetic current is formed. Then at $\mathrm{t}=0.5 \mathrm{~s}$, the motor starts to speed up to $1000 \mathrm{rpm}$. At $\mathrm{t}=2 \mathrm{~s}$, the reverse speed, the motor starts to reverse to $-1000 \mathrm{rpm}$. In order to test the system ability, low speed range of $1 \mathrm{rpm}$ is also applied in the simulation. This section provides evaluation of HIL results of speed response. The evaluation of difference speed control strategies for the two-mass system is shown in Figure 5 and Table 1.

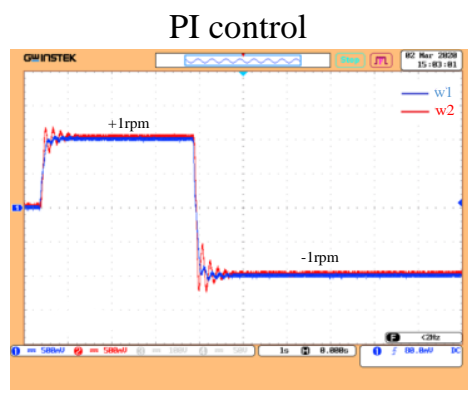

Flatness-based control

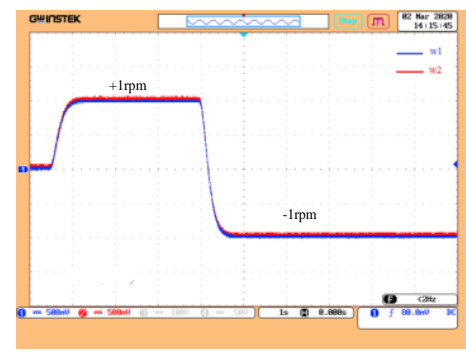

(a)

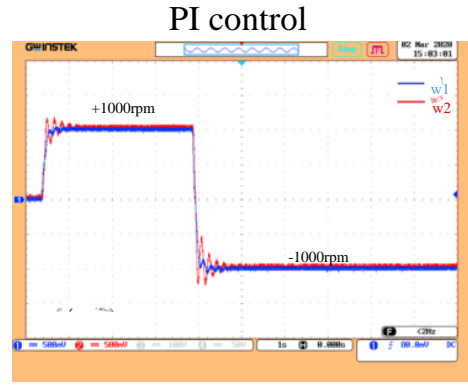

Flatness-based control

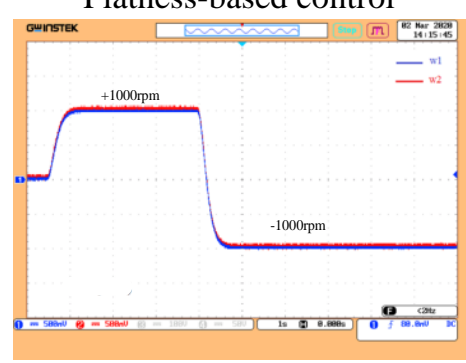

(b)
Backstepping method

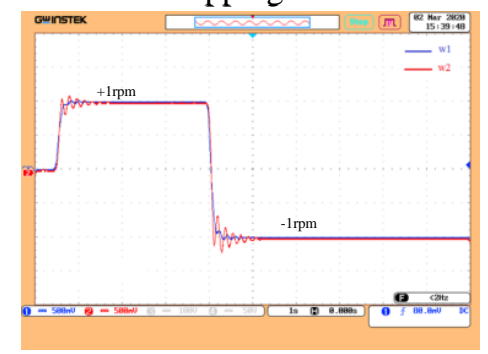

Backstepping method

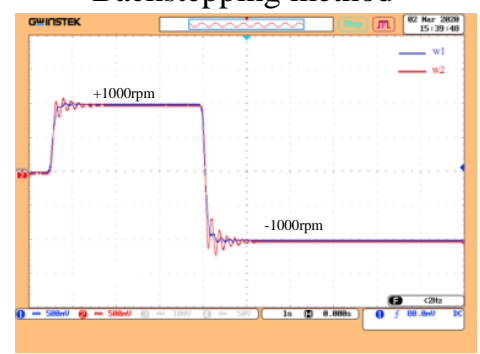

Figure 5. Speed response of Simulation/HIL platform at, (a) $\pm 1 \mathrm{rpm}$, (b) $\pm 1000 \mathrm{rpm}$ 
Table 1. HIL results of the speed response

\begin{tabular}{|c|c|c|c|c|c|c|}
\hline \multirow[b]{2}{*}{ Speed control } & \multicolumn{3}{|c|}{ At the speed of $\pm 1 \mathrm{rpm}$} & \multicolumn{3}{|c|}{ At the speed of $\pm 1000 \mathrm{rpm}$} \\
\hline & Deadbeat PI & $\begin{array}{l}\text { Deadbeat } \\
\text { Backstepping }\end{array}$ & $\begin{array}{l}\text { Deadbeat } \\
\text { Flatness }\end{array}$ & Deadbeat PI & $\begin{array}{l}\text { Deadbeat } \\
\text { Backstepping }\end{array}$ & $\begin{array}{l}\text { Deadbeat } \\
\text { Flatness }\end{array}$ \\
\hline Accelerating time (s) & 50 & 50 & 0 & 50 & 50 & 0 \\
\hline Speed settling time (s) & 2.5 & 2.0 & 1.0 & 3.0 & 2.5 & 1.0 \\
\hline
\end{tabular}

It is found that the nonlinear control method based on the flatness-based control principle gives better performance than the PI and backstepping controls, as the referenced load speed match with motor speed after a short period of time, 0.3 seconds at $( \pm) 1 \mathrm{rpm}$ and 0.5 seconds at $( \pm) 1000 \mathrm{rpm}$ (at up and reverse speed), without overshoot. That implies the speed controller based on the flatness-based control can suppress resonance oscillation over the entire operating range of the IM motor.

From the results, it can be seen that the two-mass system with flexible couplings when operating at the speed of $( \pm) 1000 \mathrm{rpm}$ and even at the low speed range $( \pm) 1 \mathrm{rpm}$, the nonlinear control method, based on the flatness-based control, has proved its advantage by solving the problem of resonant vibration suppression at the spindle compared to the PI controller and backstepping. Besides of at times of transition with fast setting time, without overshoot and load speed match with motor speed. In the following simulation scenario, the motor is set in field-weakening region. The magnetizing current responses are shown in Figure 6 and Figure 7. The three control methods show stable operation not only in nominal but also field weakening range. However, it can be seen that the flatness-based control gives better transient response, i.e., without overshoot, as seen in Figure 7, and shorter settling time (0.2s in comparison with $0.5 \mathrm{~s}$ for PI control and backstepping method).

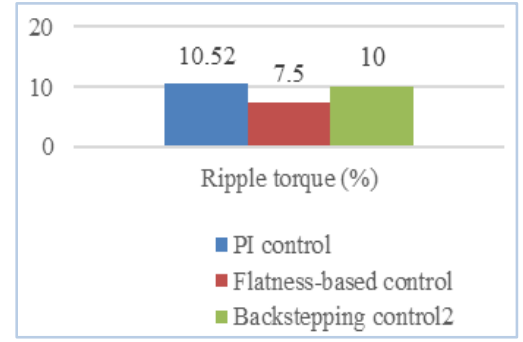

(a)

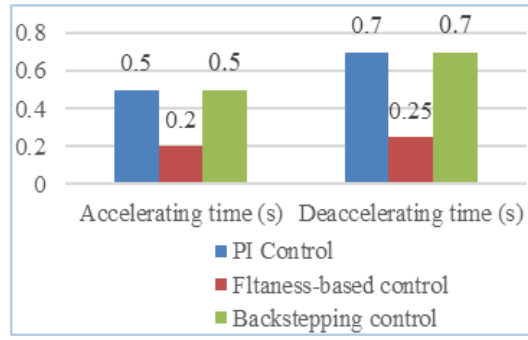

(b)

Figure 6. (a) Torque responses, (b) Speed responses
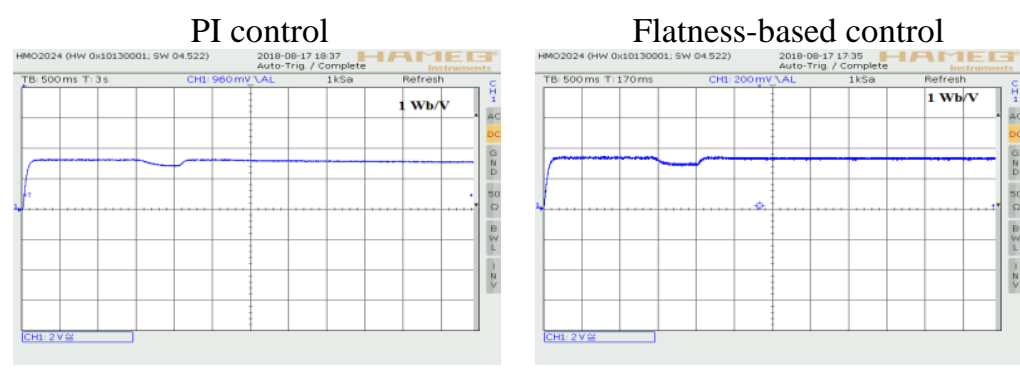

(a)

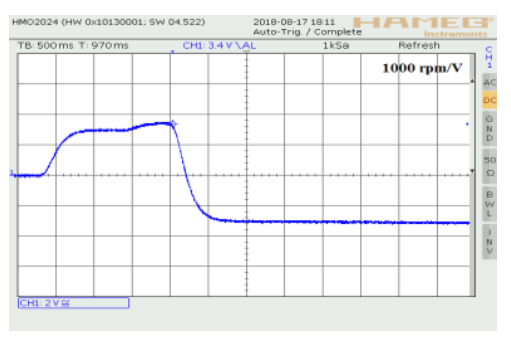

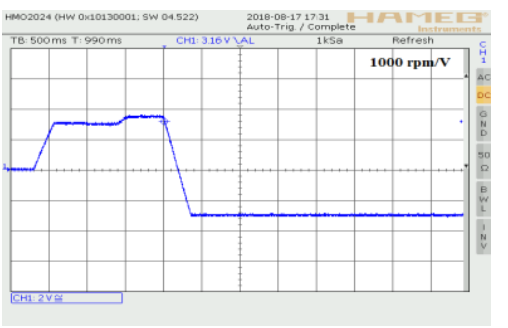

(b)
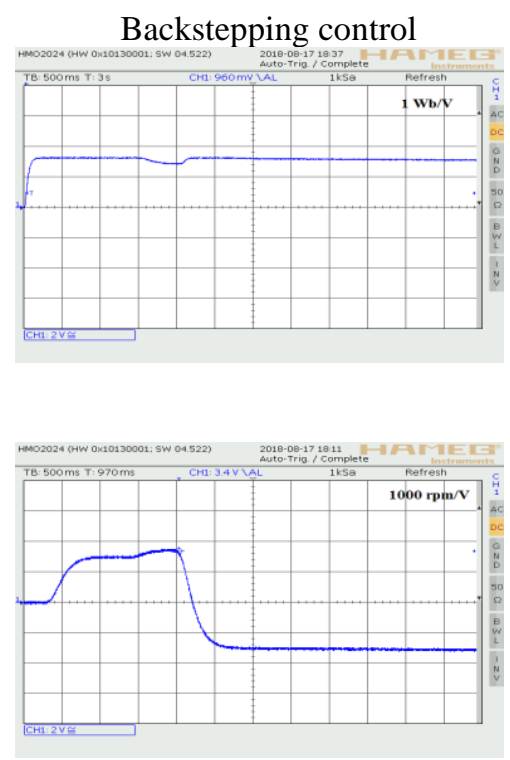

Figure 7. Controlled system performance, (a) Flux responses, (b) speed responses 

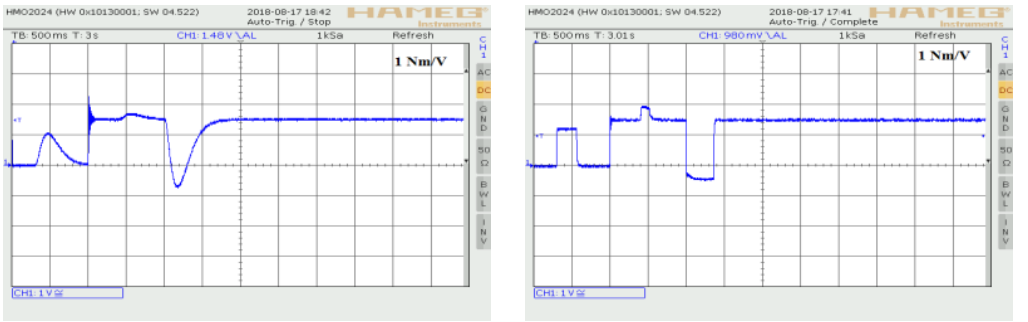

(c)

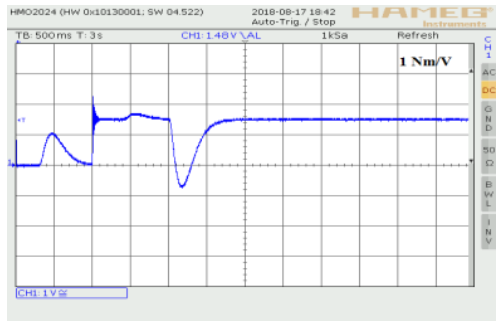

Figure 7. Controlled system performance, (c) torque responses (continued)

\section{CONCLUSION}

In this paper, the two-mass system with flexible couplings comprising of an induction motor and a load is considered. At the motor side, the current response is assumed to be ideal leading to a simplified system model. PI control, Flatness-based control, and backstepping control are employed to solve flux and speed control problems of the system. The HIL based test shows better control performances of flatness control compared to the other two schemes. This conclusion implies possibility of practical uses of flatness control in dealing with systems with flexible couplings. In the future research, in order to give a concrete evaluation, robustness experiments against varying system parameter and load disturbances will be carried out.

\section{REFERENCES}

[1] V. T. Ha, N. T. Lam, V. T. Ha, and V. Q. Vinh, "Advanced control structures for induction motors with ideal current loop response using field oriented control," Int. J. Power Electron. Drive Syst., vol. 10, no. 4, pp. 17581771, 2019.

[2] D. Łuczak, "Mathematical model of multi-mass electric drive system with flexible connection," 2014 19th Int. Conf. Methods Model. Autom. Robot. MMAR 2014, 2014, pp. 590-595.

[3] C. Ma and Y. Hori, "Backlash vibration suppression control of torsional system by novel fractional order PIDk controller," IEEJ Trans. Ind. Appl., vol. 124, no. 3, pp. 312-317, 2004.

[4] P. J. Serkies and K. Szabat, "Model predictive control of the two-mass drive system with mechanical backlash," Comput. Appl. Electr. Eng., vol. 9, pp. 170-180, 2011.

[5] M. Mola, A. Khayatian, and M. Dehghani, "Backstepping position control of two-mass systems with unknown backlash," 2013 9th Asian Control Conf. ASCC, 2013, pp. 1-6.

[6] J. Vittek, V. Vavrúš, P. Briš, and L. Gorel, "Forced dynamics control of the elastic joint drive with single rotor position sensor," Autom.-J. Control. Meas. Electron. Comput. Commun., vol. 54, no. 3, pp. 337-347, 2013.

[7] S. Brock, D. Zuczak, K. Nowopolski, T. Pajchrowski, and K. Zawirski, "Two approaches to speed control for multi-mass system with variable mechanical parameters," IEEE Trans. Ind. Electron., vol. 64, no. 4, pp. 33383347, 2016.

[8] J. Rigelsford, "Intelligent observer and control design for nonlinear systems," Ind. Robot An Int. J., vol. 27, no. 4, 2000.

[9] S. E. Saarakkala, M. Hinkkanen, and K. Zenger, "Speed control of two-mass mechanical loads in electric drives," 2012 IEEE Energy Convers. Congr. Expo. ECCE, 2012, pp. 1246-1253.

[10] S. Thomsen and F. W. Fuchs, "Flatness based speed control of drive systems with resonant loads," IECON Proc. (Industrial Electron. Conf.), 2010, pp. 120-125.

[11] L. T. Thi, L. N. Tung, C. Duc Thanh, D. N. Quang, and Q. N. Van, "Tension regulation of roll-to-roll systems with flexible couplings," in Proceedings of 2019 International Conference on System Science and Engineering, ICSSE, 2019, pp. 441-444.

[12] J. Kabzinski, "Adaptive control of two-mass drive system with nonlinear stiffness," Przeglad Elektrotechniczny, vol. 1, no. 3, pp. 51-56, 2018.

[13] S. Zhao and Z. Gao, "An active disturbance rejection based approach to vibration suppression in two-inertia systems," Asian J. Control, vol. 15, no. 2, pp. 350-362, 2013.

[14] H. Ikeda, T. Hanamoto, T. Tsuji, and M. Tomizuka, "Design of vibration suppression controller for 3-inertia system using Taguchi Method," Int. Symp. Power Electron. Electr. Drives, Autom. Motion, SPEEDAM, 2006, vol. 2006, no. 3, pp. 1045-1050.

[15] H. Ikeda and T. Hanamoto, "Fuzzy controller of multi-inertia resonance system designed by differential evolution," 2013 Int. Conf. Electr. Mach. Syst. ICEMS, 2013, vol. 3, no. 2, pp. 2291-2295.

[16] R. Zhang and C. Tong, "Torsional vibration control of the main drive system of a rolling mill based on an extended state observer and linear quadratic control," JVC/Journal Vib. Control, vol. 12, no. 3, pp. 313-327, 2006.

[17] Y. Hori, H. Sawada, and Y. Chun, "Slow resonance ratio control for vibration suppression and disturbance rejection in torsional system," IEEE Trans. Ind. Electron., vol. 46, no. 1, pp. 162-168, 1999. 
[18] D. Luczak, P. Siwek, and K. Nowopolski, "Speed controller for four-mass mechanical system with two drive units," Proc.-2015 IEEE 2nd Int. Conf. Cybern., CYBCONF, 2015, pp. 449-454.

[19] M. Valásek, "Design of nonlinear control of nonlinear multibody systems," in Virtual Nonlinear Multibody Systems, vol. 103, pp. 263-278, 2012.

[20] K. Nowopolski, B. Wicher, D. Łuczak, and P. Siwek, "Recursive neural network as speed controller for two-sided electrical drive with complex mechanical structure," 2017 22nd Int. Conf. Methods Model. Autom. Robot. MMAR, 2017, pp. 576-581.

[21] K. T. Nam, S. J. Lee, T. Y. Kuc, and H. Kim, "Position and velocity estimation for two-inertia system with nonlinear stiffness based on acceleration sensor," Sensors (Switzerland), vol. 16, no. 1, pp. 1-10, 2016.

[22] P. Serkies, "Comparison of the control methods of electrical drives with an elastic coupling allowing to limit the torsional torque amplitude," Eksploatacja i Niezawodnść, vol. 19, no. 2, pp. 203-210, 2017.

[23] G. Zhang and J. Furusho, "Speed control of two-inertia system by PI/PID control," IEEE Trans. Ind. Electron., vol. 47 , no. 3, pp. 603-609, 2000.

[24] K. Szabat and T. Orlowska-Kowalska, "Vibration suppression in a two-mass drive system using PI speed controller and additional feedbacks-comparative study," IEEE Trans. Ind. Electron., vol. 54, no. 2, pp. 1193-1206, 2007.

[25] V. T. Ha, N. D. N. Le Trong Tan, and N. P. Quang, "Backstepping control of two-mass system using induction motor drive fed by voltage source inverter with ideal control performance of stator current," Int. J. Power Electron. Drive Syst., vol. 2088, no. 8694, pp. 720-730, 2019.

[26] V. T. Ha and N. P. Quang, "Flatness-based control design for two-mass system using induction motor drive fed by voltage source inverter with ideal control performance of stator current," Engineer of the XXI Century, Springer, Cham, pp. 39-50, 2020. 